\title{
The Evolution of Public Hygiene and Sanitary Facilities in the Context of Urbanization Processes and Social Conditions
}

\author{
Anna Jaglarz \\ Wroclaw University of Technology, Department of Architecture \\ St. Prusa 53/55, 50-317 Wroclaw, Poland \\ anna.jaglarz@pwr.wroc.pl
}

\begin{abstract}
The evolution of public places and facilities for personal hygiene is directly related to the history of urbanization and to people awareness of public health and its relationship to sanitation. Throughout history, this awareness has varied extremely both between cultures and periods and produced widely disparate responses in spite of virtually identical needs. Availability of technology, variable over the centuries, was dependent on the social and cultural requirements of the times. On the one hand, the new technologies developed in order to meet the growing needs, on the other technological achievements were ignored and not used by years. An example can be a legacy and the inheritance from civilizations such as the Cretans and Romans who accomplished amazingly great feat as regard engineering and the production of hygienic and sanitary facilities, with supplying the warm and cold running water, flushing systems, steam rooms and a lack of such appliances centuries later, when because of the civilization development the basic technology would seem to be far more advanced. It is possible to say that the form of hygienic and sanitary environment of man has always been reflecting the social and economic aspects, which are a consequence of widely understood, changeable, both individual and social needs, and of the cultural and technical progress of civilizations resulting from them. Experiences and achievements of previous generations are a base of the contemporary model of the societies life. Understanding and analysis of the contemporary needs related to public hygiene and sanitary area and possibilities of its shaping should be based on an analysis of earlier experiences in this field.
\end{abstract}

Keywords: public health, public hygiene, public bathing, hygienic practices, public hygienic-sanitary facilities, public bath, public toilet, public restroom, public bathrooms design, development of public hygienic-sanitary spaces, history of urbanization.

\section{Introduction}

Hygienic procedures have been known for centuries, however their purpose is changed. Our ancestors washed themselves mainly in order to cool the body. Removal of natural smell from the skin have become the most important for us. It is a insistent 
desire to get rid of one of the animal features, because none of animals would not want to give up this basic distinctive identification, confirming a separate identity and the membership of the specific group. Yet there is a certain inconsistency in the proceedings of human. On the one hand he removes his personal smell, on the other he willingly uses of perfume and toilet waters, so he still wants to stand out with exactly a smell.

Attitude to hygiene and health over the centuries was associated with the formation of moral rules and standards. Introduction of physical distance and assimilation of standards concerning morality and shame followed gradually. Human sensibility changed. The expansion of the culture into the intimate space of the man followed. Also awareness of health and medicine increased. The approach towards hygiene and ideas of it changed and evolved with the social modifications of behaviors and customs and with the expansion of medical awareness, leading to the contemporary aseptic model of the cleanness and the contemporary forms of public hygiene and sanitary facilities.

History of the body cleanliness and public hygiene shows primarily the changeability of hygiene and sanitation habits and practices or even ideas related to water over centuries, and the gap between the past and the present.

\section{Shaping the Concept of Hygiene and Methods of Its Appreciation over the Centuries}

In ancient Greece and Rome the care of the body cleanness and hygienic procedures taking place in public scenery and the recreational circumstances were a visiting card of the free citizen. In no other civilization, public bathing was not so great social significance as in Ancient Rome, where the public baths were a main center for cultural and social life. Bath houses held the same positions that in other societies, institutions such as restaurants, urban squares, spas, sports and recreations centers. In the thermal baths people discussed, rested, played, created poems and philosophical treatises. Public baths were above all a place of socializing for the Romans.

In the Middle Ages, public bath houses were very popular, but they were not the institutions of hygiene. They were a sources of many pleasures. Medieval swimming and bathing establishments played the role of entertainment and fun places. Erotic bath prevailed over bath for washing. Water as a environment of physical delights and a source of sensual pleasures attracted more than a process of cleansing and care of the skin condition. A wine, a food, a music and alcoves with curtains were an indispensable elements supplementing the medieval bath.

From the end of the Middle Ages, when the liquidation of the public baths was ordered due to epidemics, and the baths were considered as harmful to health, while water was recognized as a dangerous cause of diseases, up to the mid-eighteenth century, hygiene, was held in fact, without the use of water. Cleanliness was unknown to the body except the face and hands, the only visible parts of it. Hygienic treatments were focused on what has been noticeable. The neatness of clothes, emphasized particularly by the collar and cuffs was a real indication of the purity. The adoption of the 
above assumptions was associated closely with the concept of hygiene, which rejected water as dangerous, having the ability to penetrate everywhere substance. Hygienic processes were to be held "dry", therefore, they have been limited to perfuming and wiping.

The situation changed at the end of the eighteenth century. Skin contact with the water was recommended as a result of healthcare argumentation. Water stimulated and washed the areas covered by clothes in order to strengthen them. The appearance was not so important as the hardening of the body and taking care of fitness and vigor. The cleanness had a specific physical usefulness and its scientific justification was possible. Cleaning provided the health care, strengthening the body and correct functioning of the organism. The cleanness, which was an expression of aesthetics in the seventeenth century, has become functional. The concept of public cleanliness had appeared as a origin of what was supposed to develop in the nineteenth century. People began to notice the connection between the lack of cleanliness and diseases. First projects connected with urban spaces and water supplies came into existence in this time. The idea of water available for each became more and more real. Public baths offering also hydrotherapy were willingly built. Spas objects having a medical approval and a social prestige, have become very popular. These institutions acted the significant part in the legitimization of water.

The word "hygiene" came into common use at the beginning of the nineteenth century. It didn't define health only, but all funds, abilities and skills used to maintenance of health. People wanted to be healthy and at the same time were convinced that to achieve this they must take care to maintain the purity of the body. Hygiene handbooks which have appeared, persuaded to certain practices, for example using of soaps. Washing has come to mean the aseptic, which had a great relationship with discoveries made by Pasteur. Microorganisms, bacteria, viruses have become a cause of the real turning point in the purity criteria.

Widespread fear of the water reigning from the Renaissance to the late nineteenth century led to equality between social classes when it comes to hygiene. This equality started to walk away into oblivion along with the "hygiene and health awareness". The threat of diseases caused that the widening gap between rich and poor, was not only unpleasant but also dangerous. Public baths and laundries were built in order to cope with difficult-task of improvement the sanitary conditions the poor lived in which. But the large public bath complexes that came into being was intended not only for the lower classes. Public bathing establishments were also popular in the first half of the twentieth century, and in some cultures, a strong tradition of public baths have remained to this day and still supports a common, social ablutions.

\section{The Evolution of Public Hygienic and Sanitary Spaces, Buildings and Facilities}

\subsection{Ancient Times}

The first evidence of the actual functioning of hygiene and sanitary facilities for public use are derived from the Cretan Knossos, and their history dates back to around 
1700 BC. These objects turn out to be surprisingly sophisticated in their design and technology, while in many respects different from ones functioning today. Most of the large cities in the ancient world were similarly advanced when it comes to availability of hygienic and sanitary facilities, both intended for the local population, as well as accessible to tourists. They were intended primarily to broad application and popularization of municipal objects, which were to replace and complement deficiency in the field of private bathrooms.

The history of public baths began in Greece in the sixth century BC. The attitude of Greeks to the bath was rather practical, without mystical references. They took a bath and showers for keeping the purity of body, for refreshing themselves in heat, after the journey, after the fight, after the gymnastics and exercises. However, the bathing wasn't for them only the simple relax after the muscle effort, but it was also helpful in keeping the mind and body in harmony. Cold baths were closely related to sports and military exercises. Warm baths were practiced only if they were prescribed by Hippocrates, because it was suspected that they caused the delicate and effeminate body, while cold water caused that body was forceful and prepared to fight. Cold water tempered both body and character.

Louterion - shallow, circular basin based on a pedestal, reaching to about the hip was the first form of public baths. It was located in the open air, in the shade of olive trees, near palestra - a place for gymnastics and exedra - a place for philosophical debates. The woman rinsed herself with water, when man - the gymnast - washed himself before exercises. Next he covered his body with oil and sand. After exercises he scraped off it along with the dirt and sweat that was the result of his efforts, using a small, curved tool made from iron or bronze called strigil. A bit later, when palestra was converted into the appropriate room of exercises, baths became their essential part. Delphi baths consisted of at least ten marble basins, hung on poles over the heads. The whole was surrounded with jaws of lions, from which water leaked. It was a kind of shower. Special hangers were designed on the clothes. When physical training had become even more significant part of the life of the Athenians, the baths adjacent to the gymnasium became larger and more sophisticated. Baths were covered and equipped with a typical bath with a depth of about $20 \mathrm{~cm}$. Their bottom was slightly sloping, which aided the outflow of water. The Greeks used them in the following way - sitting on a small stool in the water up to the calf, poured over themselves with trickles of water using the special spoon or the sponge. This bath has been reserved for occasions when a man was particularly tired. The Greeks also used large, shallow, circular pool, with rows of degrees surrounding the edge, in which they could rinse itself with the help of the sponge. It was the perfect place to sit and relax in the water before the learning of philosophy.

In the days of the Roman Empire the bath wasn't only hygienic procedure, but also a pleasure. In Rome, as in Greece, the cold water was a symbol of the health, stimulated the body, proved the masculinity and the hardness of character. The Romans didn't treat their body as the object of the aspiration to the ideal of the beauty, didn't derive satisfaction from it, in contrast to the Greeks. They meant rather the health care, keeping the purity and, most important, experiencing of the pleasure. 
Ancient Rome and Roman amazing baths can be regarded as a basic pattern, on which the development of the contemporary forms and technologies of public hygienic and bathing services is based. Baths, originally intended as municipal institutions available to all for free or for a small fee, with increasing prosperity of societies began to develop in the direction of separation of the individual services and facilities. In every Roman town was at least one public bath and, if necessary, aqueduct, which supplied bath and public wells. The real era of public baths began actually in 19 BC, along with the construction of the thermal baths by Agrippa. Thermal baths were a kind of recreation center equipped with the stadiums and swimming pools, but also gardens and promenades. There were also eateries and rooms for rest and relaxation. Libraries and theatres provided pleasures connected with the culture. Thermal baths were a place of entertainment, games, social events, as well as political, literary and artistic debates.

Public baths were designed for simultaneous using by thousands of people. Everyone used them - the rich and the poor, women and men, slaves, thieves, prostitutes. Roman baths built by successive rulers were larger and grander than ever before. Building such large complexes would not be possible without new technologies and significant progress in Roman architecture. Plan of the bathing structure was a combination of regularity and diversity. Rectangular shaped main room, cella media, was covered with the cross vault, however surrounding them smaller, round or polygonal rooms, were covered with domes. Brick and cement structures were being covered inside with decorative, smooth or relief, facings. The walls and some floors, and even the bottom of the pools were decorated with mosaics. They presented the forms of fauna and flora, marine deities and human figures. Marble was dominant finishing material, but gold, precious stones and ivory were also used. The walls were decorated with figures of nymphs, monsters, warriors and athletes. Seats and bases of washbasins were richly carved. The water gushed from silver taps. Numerous oblong, rectangular and oval, marble baths were available for bathers. Water was supplied by the aqueduct. Hypocaustum was applied for the heating

In the second century AD in Rome were built many public latrines. Impurities from them flowed down channels to the Tiber. The oldest of them, the channel cloaca max$i m a$, is functioning until today. Every latrine was equipped with about twenty marble seats situated side by side, surrounded by grooves with continually flowing water. Consoles, usually in the shape of dolphins, were supports for hands and simultaneously were partitions between the seats. Even the majestic latrines in the imperial palace were equipped with three adjacent seats. There were also latrines in the form of a trough, along which from both sides wooden seats were attached.

The real example of the urban public sanitary equipment designed for men, urinal, called pissoir or Vespasienne, appeared for the first time in ancient Rome. In the first century AD the Roman Emperor Vespasian decided, as part of a recovery plan of the city, to build urban urinals for the public convenience. In contrast with public latrines, for the use of earthenware jug, placed in front of fulling workshops (urine collected in them was a valuable raw material used for felting, dyeing and cleaning of fabrics), the Romans didn't need to pay. However owners of workshops had to pay the tax on the unpleasant smell imposed on them by the emperor. It was an effective way allowing 
to assure both continuity of production for workshops, as well as making rich the emperor's treasure trove, and at the same time dissuading citizens from urinated in the random places.

\subsection{The Middle Ages}

Comparing medieval Europe to the Mediterranean lands from the period of greatest development of Greece and Rome, it is easy to notice the backwardness of Europe in terms of the sanitation. While focusing on Europe, it can be observed that the era of the Middle Ages was however a remarkable period, when it comes to hygiene.

Up to times of the Middle Ages people inhabiting Europe were largely primitive, characterized by an underdeveloped economy and technology. But even then certain needs to keep hygiene existed and were practiced.

The Middle Ages is very long period, during which the general development followed, so the formation of states and the development of art, technology, improving the standard of living. Thanks to the enlargement of the settlements and the cessation of migration became possible to build long-lasting buildings, also public baths. Of course, washing or bathing is the most important aspect of hygiene. In the Middle Ages the bath was nothing special, it was applied not only to hygienic purposes, but also for pleasure. Its health benefits were also appreciated. People walked to the baths with their families, took clothes off already at home in order to avoid its destruction or theft, walked on the streets only in towels. Separate bath buildings were built at each of the castle. They were also common in most towns and villages. These facilities were a places of rest, where in addition to body washing was the ability to refresh themselves, conversations and plays. Steam baths, acquired from Scandinavian nations, were very popular in Poland and Russia. Fireplace, which from time to time was being poured with water in order to create steam, was placed in one of the corners of the wooden room sealed with resin. The excess of the smoke could get away through the openings in the roof. These baths were willingly visited by both the Polish rulers of the Piast and Jagiellonian dynasties, as well as their lieges, even the poorest, because in many such institutions one day a week was appointed as a free bath for beggars.

The population inhabiting cities took a bath primarily in the public baths. In the country the practice of the bath was not less popular than in the city. In order to wash, the person squatted in the small wooden tub with hot water placed at home or outside the house, under expanded bed sheet, what imitated the bath room. The bath was usually taken collectively - in two or more persons. Hospitality and social custom favored keeping rituals, such as shared bath of growers or bath preceding the wedding day (the groom was taking it among his companions, the bride, accompanied by her friends). Villagers also used open bodies of water, gushing sources or hot springs called either natural or wild. Some villages had a public baths, where baths were supplemented by medical treatments. At the end of the Middle Ages custom of taking a bath, whether water bath or steam bath, at home or in the public bath, became a universal phenomenon in almost all social environments. In the Middle Ages the both public and private bath took place in wooden tubs with round and oval iron rings. 
They were placed in the bedrooms. Metal bathtubs came into use in the fourteenth century. Water heating methods have been improved - the wooden tub was filled using the tube linked to the boiler with hot water standing on small stove. Metal bathtubs were also placed directly over the heat source.

In the Middle Ages, amongst the universal ignorance, as regards the sanitation, lack of interest in the development of assistive devices for meeting physiological needs such as urination and defecation was noticeable to about 1500. Development of cities such as London and Paris took place without appropriate channel systems. Municipal sewage flowed in gutters into the rivers, which were the source of drinking water for the people. Public latrines were also placed directly by the rivers. People used the chamber pots called lasana or chairs with a holes called sellae petrusae, which were emptied into vats or the pit under the staircase. The content was often poured out the window directly into the street, to the detriment of passers-by. This habit outlasted quite a long time in Paris. For comparison, in the medieval Hanseatic Gdansk, latrine was located near every house, in the corner of the yard. Hanseatic cities were planned precisely and the problem of garbage collection and disposal was resolved by sanitary regulations. In Gdansk backyard privy was a part of the architectural plan - the first latrines appeared there along with the first residents. But not everywhere it was a rule. In Plock, or the Norwegian Bergen and Oslo latrines were built much later. Initially, no one cared too much about hygiene and outbuildings were used as latrines.

It is no wonder that medieval cities were horrible stinking. Unpaved streets were dirty, because people didn't refrain from pouring filth out the window. In order not to get bogged down in the mud, people walked on the boards, which were placed every few years anew. Level of the streets was rising quickly - in some cities, streets layers from the thirteenth century there were at least four meters below today's street level. Cesspits placed in the courtyards of medieval houses filled up within a couple of years, after which they had to be emptied. The structure of the latrine, depending on conditions and materials from which it was built, could be used for 150-200 years. Earlier latrines were generally smaller than later. They were mostly wooden structures, but sometimes latrines were made of brick and stone. The shape of the stone latrine could be resembling a well - it happened that exactly wells converted into latrines. Conventional latrines and privies, however, were made of wood. Hay and moss were used as a toilet paper.

\subsection{Early Modern Period - From 16th to 18th Century}

From the beginning of the sixteenth century, both practices - bath at home and bath in the public baths - started to disappear gradually. It was related with characteristic fear of epidemic and disease transmission by the water. Rejection, or "condemnation" of bath became all the more distinct, that this practice had earlier own institutions and a methods. Within the following years failure of hygiene took place in entire Europe. Public baths began to disappear from the towns and villages, and the ones that remained had a bad reputation of debauchery places and the sources of all diseases. Baths disappeared, and with them practice of the communal bathing. By the start of 
the reign of Louis XIV in France functioned only two public bath establishments, which were officially registered. But these specialized in therapeutic steam baths recommended by doctors, in the hair removal treatments, and assisted informal social meetings. In England a hundred years later there were several public baths in London offering similar services.

Bathing enthusiasts could also use river bathing or spas and thermal springs. Around 1750, the first in aristocratic circles, water was slowly reintroduced as an essential element of maintaining bodily hygiene. This was the first step in the process that ultimately led to the reactivation of the public bathing. There were also opinions from a growing number of doctors convinced of the positive effects of regular hot and cold baths.

Development of public sanitary facilities, just as of hygienic devices and practices, didn't have its continuation in the large part of the Western World for a long time. They didn't exist at all, or their role was fulfilled by appointed places of manure storage or very primitive latrines. Wealthy passengers used special chamber pots being a part of carriages equipment. Appropriate chamber pots occurred also in new latrines. They were in common use. Depending on the social class of the user they were ordinary made of copper or faience, or silver, richly decorated. Unfortunately, scruffy habit of pouring their contents directly into the street still remained. Similarly the habit of public meeting the physiological needs such as urination and defecation was impossible to eradicate. In Versailles, which in the seventeenth century did not have a sewage system, but was equipped with three hundred portable "closed stools - toilets", hygiene of urination and defecation was still ignored. We should pay attention to the social problem of using the toilet. On the analysis basis of earlier social behaviors associated with it, it is easy to notice, that the idea of the privacy and intimacy of meeting personal physiological needs such as urination and defecation turns out to be quite modern phenomenon. In the time of Louis XIV, the residents of Paris and surrounding areas impatiently waited for dusk to take advantage of the open space. The view of streets reminded of human weaknesses. Unfortunately such a situation was a serious impediment for the ones who preferred privacy and a place to sit. Recommendations on these issues didn't appear until the late sixteenth century.

It should be noted that the sixteenth century was a turning point in terms of the development of private and public toilets. In France in 1519, the Norman government imposed on citizens an obligation to have a toilet in every house. In India, the Mughal Jahangir king ordered to build a public sanitary devices for more than a hundred residents of Alwar. However such actions didn't become a principle, and what's more, belonged to rare exceptions. In addition, to emphasize the contrast between then Europe, and the Arab World in this respect, it is worth mentioning that while the Hindu palace residents used the marble flush toilets, London until to 1700 didn't have running water, and the majority of European citizens still counted on chamber pots and "holes in the open air."

At the end of the eighteenth century, after a period of obvious avoidance essential for the present devices, clockmaker from London, Alexander Cummings, patented flushed toilet and proved to be a precursor of the present toilet model. Then it was improved by the English manufacturer of furniture, Joseph Bramah, which began 
production of a large number of toilets, in the form of cast iron toilet bowls. However, the majority of cities still wasn't equipped with the sewage system. People used latrines and chamber pots.

\subsection{Modern Era - 19th and 20th Century}

In the early nineteenth century in Paris alone, the services associated with hygiene, as well as with pleasures, were provided by the staggering total of seventy-eight public baths. However only the second-half of the nineteenth century brought evidence of the recovery of social awareness about the problem of public hygiene and sanitation in the cities.

An imposing bathing establishment called the Thermes Parisiens was opened in Paris in the 1850. A wide range of various baths and treatments available in the shared and private rooms was advertised in brochures. Guests could enjoy the communal Russian sauna, private rooms with hot air for the dry bath, Turkish bath with the Byzantine decor, numerous studies with beds for massage, relaxation rooms, swimming pool replenished with a constant supply of hot and cold water gushing from a fountain. All of this was available in richly decorated interior with the majority of marble, glazed ceramics, mosaics and stucco.

The emphasis on luxury and physical pleasure as essential elements accompanying caring for personal hygiene contributed to the success of public baths, which were also supported by the rapid development of swimming pools in the same period. The revival of public baths allowed once again to appreciate forgotten blissful feeling resulting from contact of the skin with the water. By far the most popular bathing institutions proved to be those that were equipped with a swimming pool, allowing to combine pleasure of games and fun with the requirements of personal hygiene, which became more and more respected and encouraged. In combining with the hygienic function of the use of water, swimming baths helped to support the passion for swimming, kind of sport recommended by doctors and educators. One of the unique places in this regard was the Parisian Gymnase Nautique des Champs-Elysees, founded in 1850 in a park amid gushing fountains. The pool was in the shape of a long rectangle with a picturesque island in the middle, linked to either edge by means of little wooden carved bridges. Two tiers of galleries, divided into boxes with balconies, hidden from view by decked drapes and curtains were located on both sides of the pool. The building was covered with huge glass roof which provided excellent illumination of the interior. The roof was partly decorated with climbing plants. In very sunny and hot days the roof could be covered with white curtains. A billiard room, places for reading and conversation, rooms with beds and individual bathrooms complemented all the attractions.

The development of the public baths intended for a wide range of users started with the arrival of private bathrooms in wealthy households. These hygienic establishments became places for the masses. The bath in the tub had been replaced by the shower bath which was more practical, quicker and made possible of using less water than bathtub. About 1900 public baths with showers became the institutions intended for the working classes. In the United States the history of public baths had a similar 
course to European countries - France, England and Germany. Even before the end of the nineteenth century, experts in health and public hygiene commenced their action directed at popularizing the cleanness. They demanded a public bath, the use of which would be free of charge. Such objects appeared in New York in the early twentieth century. They were equipped with showers, and the costs for upkeep and running costs were kept to the minimum in order apart from the bath they could provide even soap and towels for free. However in spite of these conveniences, increasing possibilities of a bath in private bathroom in own home resulted in less and less interest in public hygiene institutions. For this reason public baths were closed down.

As regards public sanitary facilities, about 1840 the public urinal regained its rank, this time on the Parisian streets. In 1860 in Paris, there were also special toilet pavilions for women, enclosed and lockable, in contrast with usually opened or only partially shielded men's urinals. In the '80s similar pavilions, public restrooms, have already been designed for both sexes, and were also equipped with a toilet bowl. We can say that in many ways these objects didn't differ much from some of contemporary public toilets. In the '80s, there was also a return of an itinerant seller of public convenience, albeit in a more refined form of vehicle equipped with a water. It was a special horse carriage, which looked like a wagon and consisted of several sections toilet cabins. Such vehicles were running on the main streets of major cities and were offering the possibilities of meeting the physiological needs for a fee.

In England, the sudden development and increase of the public toilets number was associated with the event of the World Exhibition in London in 1851, for the purpose of which toilets was designed and installed in such an amount that they could accommodate the crowds of visitors. Their equipment was supposed to reflect the quality and aspiration of exhibition. The introduction of facilities for tourists, especially visitors, traveling Europe by rail was another consequence of the great London exhibition and other similar events. Newly built stations and terminals were equipped with complete sanitary facilities, and the standard of their equipment was adapted to the class of the transport. In many ways, it was a pronounced beginning of the availability of this type of public facilities on a large scale. However a few years later, the project of sanitary engineer responsible for the installation of toilet facilities in the Crystal Palace, George Jennings, of the construction of underground toilets in subway stations in strategic locations of London was rejected by the authorities. Jennings suggested fully-fitted objects, with all the comforts and with the additional service which could receive a small fee for using them. Paradoxically his offer was rejected by the English gentlemen, who preferred to expose their wives and daughters to unpleasant visual impression associated with view of corners used by some people for certain physiological needs, as well as unpleasant bodily feelings as a result of the lack of ability of meeting own needs than to agree to the construction of facilities providing favorable conditions, privacy and intimacy.

\section{Summary}

Long-term development of public hygienic-sanitary facilities over the centuries and the final battle about their availability lasting in the late nineteenth and early twentieth 
century ended successfully and eventually they became widely available in most major cities. Most of them was designed with allocating for use of pedestrians and tourists. With a sense of spatial order and spatial composition they were entered in the development plans of cities and located, for example, in the traffic circles or at the streets dividing shopping centers. The demand for public hygienic-sanitary facilities serving urban pedestrian traffic decreased significantly since most commercial institutions and services was obliged to provide this type of facilities for the society. On the other hand, because of the condition of many municipal public toilets, people stopped using them. Despite the insignificant upgrade, some objects have survived until today in many places, and although little is needed to have their equipment again was useful, however, they are no longer available as once. Similarly, some of the former bathing institutions - when they were not longer needed, public baths were converted into museums and their previous functions would seem to have been relegated firmly to the past, along with the pleasure of using them. However, in some Western cities New York, London, Geneva, Brussels, Amsterdam and many cities in Germany - in response to new social needs, these objects are starting to work anew, offering to the possibility of using the bathtub and the shower for affordable price or even for free. The purpose is not only providing possibilities to maintain personal hygiene to people who do not have their own bathrooms, but also opportunities for social integration, which disappeared along with the public baths because of the availability of private bathrooms in the second half of the twentieth century.

\section{References}

1. Bonneville (de Bonneville), F.: The Book of the Bath, pp. 19-60. Rizzoli International Publication Inc., New York (1998)

2. Goldman Rubin, S.: Toilets, Toasters \& Telephones, pp. 3-27. Browndeer Press Hacourt Brace \& Company, Nowy Jork (1998)

3. Historia higieny, http://www. kolo.com.pl

4. Historia zapisana w latrynach, Swiat nauki, Proszynski Media sp. z o.o., Warszawa, 1 (2006)

5. Ouley, G. (ed.): Historia zycia prywatnego. T. 2: Od Europy feudalnej do renesansu. Ossolineum, Wroclaw (1998)

6. Chartieus, R.: Historia zycia prywatnego. T.3: Od renesansu do oświecenia. Ossolineum, Wrocław (1999)

7. Hryn - Kusnierek, R.: Tam gdzie krol piechota chodzi, pp. 96-99. Focus, Axel Ganz, Andreas Tilk G+J Gruner + Jar Polska, 5 (2005)

8. Jacques, R., Jean Charles, S.: Historia epidemii. Od dzumy do AIDS. Wydawnictwo W.A.B., Warszawa (1996)

9. Kira, A.: The Bathroom, pp. 193-199. The Viking Press, Nowy Jork (1976)

10. Kopalinski, W.: Opowiesci o rzeczach powszednich. Instytut Wydawniczy Nasza Ksiegarnia, Warszawa (1990)

11. Krzeminska, A.: W wodzie, winie i blocie. Polityka, Polityka Sp. z o. o. S.K.A., Warszawa, 32 (2006)

12. Lebrun, F.: Jak dawniej leczono. Lekarze, swieci i czarodzieje w XVII i XVIII wieku. Oficyna Wydawnicza Volumen, Dom Wydawniczy Bellona, Warszawa (1997) 
13. Mitrowska, M.: Po co nam kapiel? Focus, pp. 12-16. Axel Ganz, Andreas Tilk G+J Gruner + Jar Polska, 10 (2000)

14. Sokolowska, M.: Myc sie czy wietrzyc. Dramatyczne dzieje higieny od starozytnosci do dzis, pp. 6-90. Wydawnictwo Dolnoslaskie, Wroclaw (1999)

15. Szubert, M.: Leksykon rzeczy minionych i przemijajacych, Muza SA, Warszawa (2003)

16. Vigarello, G.: Czystosc i brud. Higiena ciała od sredniowiecza do XX wieku. Wydawnictwo W.A.B., Warszawa (1996)

17. Vigarello, G.: Historia zdrowia i choroby, Od sredniowiecza do wspołczesnosci. Oficyna Wydawnicza Volumen, Niezalezna Oficyna Wydawnicza, Warszawa (1997) 